\title{
Article
}

\section{The Effect of Enrichment Filling and Engagement Time on Regurgitation and Reingestion Behaviour in Three Zoo-Housed Orangutans}

\author{
Rebecca Nash ${ }^{1}$, Helen Johnston ${ }^{2}$, Amy Robbins ${ }^{3}$ and Kris Descovich $1,4, *$ (D) \\ 1 Environmental and Animal Sciences, Unitec Institute of Technology, Auckland 1025, New Zealand; \\ rebecca.nash@aucklandzoo.co.nz \\ 2 Independent Researcher, Melbourne 3226, Australia; helen.johnston13@gmail.com \\ 3 Auckland Zoo, Auckland 1022, New Zealand; amy.robbins@aucklandzoo.co.nz \\ 4 School of Veterinary Science, University of Queensland, Gatton 4343, Australia \\ * Correspondence: k.descovich1@uq.edu.au; Tel.: +61-490-370-334
}

Citation: Nash, R.; Johnston, H.;

Robbins, A.; Descovich, K. The Effect of Enrichment Filling and

Engagement Time on Regurgitation and Reingestion Behaviour in Three Zoo-Housed Orangutans. J. Zool. Bot. Gard. 2021, 2, 10-20. https://doi.org/ $10.3390 /$ jzbg2010002

Received: 21 October 2020

Accepted: 3 December 2020

Published: 14 January 2021

Publisher's Note: MDPI stays neutral with regard to jurisdictional clai$\mathrm{ms}$ in published maps and institutional affiliations.

Copyright: (C) 2021 by the authors. Licensee MDPI, Basel, Switzerland. This article is an open access article distributed under the terms and conditions of the Creative Commons Attribution (CC BY) license (https:// creativecommons.org/licenses/by/ $4.0 /)$.

\begin{abstract}
Regurgitation and reingestion $(R / R)$ is a prevalent, abnormal behaviour observed in captive great apes. $R / R$ may be related to animal welfare and while less $R / R$ appears to occur when apes are provided with browse and continuous foraging opportunities, the aetiology of the behaviour (e.g., foraging time or taste characteristics such as sweetness) is not well understood. This study aimed to determine how environmental enrichment may affect $R / R$ in three zoo-housed, adult orangutans. Over eight weeks, nine fillable enrichment items were provided twice to each orangutan-once with a sweet filling and once with a savoury filling. Enrichment engagement time and $R / R$ behaviour were monitored for 1 - $h$ after the item was provided. Individual differences were found in $R / R$ occurrence. One individual was more likely to perform $R / R$ when given enrichment with a sweet filling $(p<0.05)$, and a second was more likely to $R / R$ with savoury filled enrichment $(p<0.05)$. $R / R$ behaviour from the third orangutan was unaffected by enrichment filling $(p>0.05)$, however he engaged longer with savoury filled enrichment, compared to sweet $(p<0.05)$. No relationship was found between engagement time and amount of $\mathrm{R} / \mathrm{R}$ behaviour, for any of the orangutans $(p>0.05)$. While these results should not be generalized without a larger study, they do suggest that diet and enrichment qualities may play a role in the performance of $R / R$, and individual variation should not be overlooked when considering causation.
\end{abstract}

Keywords: regurgitation; welfare; enrichment; zoo; primate; behaviour

\section{Introduction}

Contemporary zoos increasingly strive to provide husbandry that is supported by evidence-based research [1]. While many zoo-based animal welfare studies have focused on mammals, particularly great apes [2], there are still gaps in our knowledge that may prevent zoos and sanctuaries from providing optimal care. Regurgitation and reingestion $(\mathrm{R} / \mathrm{R})$ is one poorly understood behaviour observed in captive great apes, which is likely to be detrimental to welfare [1]. Lukas [3] summarises $R / R$ as the voluntary movement of food or fluid from the oesophagus or stomach, to the mouth, hand, or floor, followed by reingestion of this regurgitant. Although regurgitation may outwardly resemble vomiting, it is not an involuntary action brought on by autonomic activity or necessarily preceded by contractions of abdominal muscles and retching ([4] cited in Hill [1]).

Great apes do not regurgitate and reingest food as part of their normal feeding repertoire [5]. To date, there are no published reports of wild great apes or wild-born sanctuary great apes engaging in $R / R[1,6]$, but some anecdotal observations of $R / R$ by sanctuary-housed orangutans have been described [7]. In contrast, Hill [1] outlines that $\mathrm{R} / \mathrm{R}$ has been observed in almost all zoo-housed great ape species (e.g., chimpanzees, Pan 
troglodytes [8-10]; orangutans, Pongo spp. [11]; Bonobos, Pan paniscus [12]; and Western lowland gorillas, Gorilla gorilla gorilla [3,5,13,14], as well as various other primate species [12]. A survey of 154 orangutans ( $>4$ years) in North American zoos found that $35 \%$ engaged in $R / R$ [11], and there is evidence from Singapore Zoo that $R / R$ in young orangutans ( $\leq 7$ years) is around double that of older orangutans [15]. Another study found that out of 40 chimpanzees across six research groups in the United Kingdom and United States of America, 30\% engaged in R/R [16]. A study of 91 zoo-housed gorillas ( $>5$ years) across 17 zoos, found that $84 \%$ exhibited $R / R$ behaviour [17]. Taken together, these studies suggest that $R / R$ is a prevalent behaviour exhibited by captive great apes, and as there is no published evidence of $R / R$ being part of the normal behavioural repertoire of wild great apes, it may be classified as an abnormal captive behaviour $[1,5,18]$. Gould and Bres [17] suggest that $R / R$ exhibited by hand-reared non-human apes may also result from a failed social interaction, but this suggestion has not been investigated thoroughly. Interestingly though, a study of zoo-housed chimpanzees, found that small increases in keeper interaction (an extra 10 min per animal, 5 days a week) had positive carry over effects, including reduced incidence of R/R [19].

In humans, rumination can have deleterious consequences resulting from the acidic regurgitant, including dental erosion, motor disorders of the oesophagus, ulceration, oesophageal strictures, and pulmonary aspiration $[1,20]$. If $R / R$ in non-human apes has similar harmful physical consequences, then it will have a negative impact on their welfare. Thus far, there is no published literature detailing any negative physical consequences resulting from regurgitated oral acid by apes exhibiting R/R. However, a comparison between regurgitant and food $\mathrm{pH}$ found that the regurgitated samples were significantly more acidic than the original food, suggesting that some stomach acid had been regurgitated into the mouth [5]. Furthermore, there are anecdotal reports of sores appearing on areas of skin that make contact with regurgitated material (e.g., back of the hands, and sides of the mouth) in gorillas who engage in $R / R$ [1]. If $R / R$ is having a negative impact on the physical welfare of captive great apes, then further research is important in order to determine the cause of the behaviour and how to eliminate it.

Causality for $R / R$ is difficult to determine, however several dominant theories exist $[1,3]$. Great apes may use $R / R$ as a way to prolong feeding opportunities within a captive environment [1], and indeed, research on gorillas indicates that $R / R$ is most prevalent in the postprandial period [13]. It has been suggested that increasing the frequency of food availability (but not the overall quantity) to reflect the ubiquitous distribution of food that great apes experience in the wild ('continuous feeding hypothesis'), may reduce the occurrence of R/R [3]. Foraging makes up a large proportion of the activity budgets of wild great apes [21-23]. These foraging opportunities may not be well replicated in captive environments, potentially resulting in frustration or even hunger [1]. There is some support for this in the literature, as Hill [24] showed that increasing opportunities for continuous feeding (without changing the components of the diet), virtually eliminated $\mathrm{R} / \mathrm{R}$ behaviour exhibited by one silverback gorilla. Alternatively, it may be that particular food qualities (e.g., fibre levels or sweetness) are more influential on $R / R$ behaviour than food availability. Orangutans are primarily frugivores, however they also incorporate a wide range of other items into their diets including invertebrates, bark and leaves [25]. Their diet is strongly influenced by food availability across different habitats [25] and by early exposure to maternal food choices [26]. The composition of wild fruits generally differs from the more palatable cultivated fruits provided by zoos, which have higher sugar and lower fiber concentrations [27]. The provision of fibrous foods such as browse, rather than cultivated sweet fruit and vegetables, may decrease the incidence of $R / R$ [1] and result in other positive effects such as reduced inactivity [28]. For example, the feeding of browse to two zoo-housed gorillas increased foraging time and decreased R/R behaviour [17]. In a follow-up study, feeding time decreased and $R / R$ increased in three gorillas when their meals were blended and served as an easily digestible liquid [17]. More recently it was found that providing daily browse significantly decreased $R / R$ behaviour in three captive 
gorillas, compared to when it was provided twice or four times a week [14]. Furthermore, foraging time increased and more closely reflected wild activity budgets [14].

$\mathrm{R} / \mathrm{R}$ behaviour may not be influenced by a single causal factor. A study of four zoo-housed Bornean orangutans found that browse significantly increased the time spent feeding, resulting in a trend towards reduced R/R [11], however when sweet foods were available, a significant increase in $R / R$ was observed in two of the individuals. A case study of one male chimpanzee, who had exhibited $R / R$ for seven years, found foraging time increased and $R / R$ decreased when browse was provided daily, whereas previous attempts to replace fruit with high fibre vegetables had no effect [23]. Interestingly, there was an increase in $\mathrm{R} / \mathrm{R}$ with the provision of forage material (unsweetened cereal, sunflower seeds, peanuts, popcorn and chicken scratch) even though foraging time increased. This may be because that forage material was able to be eaten quickly, resulting in less satiety than when consuming browse [23]. When several zoos removed commercial biscuits and reduced fruit in their gorillas' diets, and replaced these with fibrous vegetables, $R / R$ significantly decreased, and was eliminated in one zoo population [29]. In summary, published and anecdotal evidence suggests that $R / R$ is less prevalent in zoo-housed great apes when they are provided with browse, however the evidence is undecided as to whether this is driven by specific aspects such as foraging time and feelings of satiation, fibre content, or taste characteristics such as sweetness.

Browse requirements for primates can be highly specific, and although daily browse may support nutrition and welfare for zoo animals, it may be difficult and expensive to source at such a frequency [30]. Therefore, other strategies that do not incorporate browse, such as the use of environmental enrichment (hereafter enrichment) may provide opportunities to promote natural feeding behaviour and the reduction of abnormal behaviour such as R/R. Enrichment broadly consists of alterations to the physical and/or social environment of captive animals [31], which importantly has animal welfare as its primary goal through the enhancement of psychological and physiological well-being [32]. While enrichment can take many forms, food-focused enrichment is often used in zoos to promote foraging behaviour that more closely reflects wild activity budgets [33]. Feeding enrichment offers an important opportunity to examine some of the potential underlying drivers of $R / R$ behaviour such as food sweetness and processing time, while controlling interacting variables.

The present study investigated the effect of feeding enrichment on the $R / R$ behaviour of three orangutans at Auckland Zoo, during a one-hour postprandial period. The aim of the study was to determine: (1) whether enrichment filling type (sweet vs. savoury) was associated with the amount of R/R behaviour; (2) how enrichment filling type affected the length of time engaged with enrichment; and (3) whether the length of time engaged with enrichment affected the amount of $\mathrm{R} / \mathrm{R}$ performed. It was hypothesised that the orangutans in the study would R/R more with sweet enrichment than savoury, and that longer enrichment engagement would correspond with lower levels of $R / R$.

\section{Materials and Methods}

\subsection{Study Animals and Site}

This study focused on three orangutans housed in a single exhibit at Auckland Zoo (New Zealand): two Bornean orangutans (Pongo pygmaeus: 35-year-old male Charlie, and 28-year-old female Melur), and one Bornean-Sumatran orangutan (P. pygmaeus $\mathrm{x}$ P. abelii: 37-year-old Wanita). All were observed to frequently engage in post-prandial $R / R$ behaviour at the time of the study [34], however Melur and Wanita developed R/R behaviour only after arrival to Auckland Zoo, potentially on exposure to other individuals performing this behaviour. The study site was the Auckland Zoo orangutan exhibit, which consisted of a $45 \mathrm{~m} \times 40 \mathrm{~m}$, kidney-shaped, open-air, on-display enclosure, and an offdisplay enclosure with two large holding areas $(\mathrm{L} \times \mathrm{W} \times \mathrm{H}: 6 \mathrm{~m} \times 9 \mathrm{~m} \times 6 \mathrm{~m}$ and $10.4 \mathrm{~m} \times 9.5 \mathrm{~m} \times 5 \mathrm{~m}$ ) and three night-rooms (all $3.9 \mathrm{~m} \times 2 \mathrm{~m} \times 2.6 \mathrm{~m}$ ), fully enclosed by wire mesh. The on-display enclosure was furnished with permanent climbing structures 
(large poles) interconnected with a complex network of climbing ropes., while an enclosed off-display dayroom had benches, poles and climbing structures. The orangutans were on exhibit during the day and only brought inside to allow keeper access for cleaning of the exhibit or for distributing enrichment. At $4 \mathrm{pm}$ the orangutans were given access to the off-display enclosure. On most nights they also had overnight access to the on-display area.

\subsection{Eenrichment Program and Experimental Protocol}

In this study, the behaviour of the three orangutans was video recorded over $60 \mathrm{~min}$ sessions, commencing when they were given enrichment items filled with an edible sweet or savoury filling. This study was conducted opportunistically in conjunction with the zoo's existing enrichment program. No experimental interventions were introduced for the purpose of this research project and all data was collected observationally therefore animal ethics approval was not required. All enrichment items and fillings used were a subset of the orangutans' usual enrichment program, which was designed by the Auckland Zoo primate team, and prepared by zoo volunteers. The overall enrichment program consisted of 54 different items/activities in total, included over a rotating 4-week schedule, with two items given each day. Enrichment included in the current study were nine objects that were non-edible but could be filled with an edible substance (Table 1). Each item was included twice, once with a filling that contained a sweet item such as jam and/or fruit in dried, stewed or juice form ('Sweet' filling) and once with a similar filling that contained no sweet item ('Savoury' filling). Prior to the commencement of each session, which occurred between 2 and 3pm (Table 1), six identical enrichment items (two per orangutan) were dispersed around the enclosure to minimize within-group competition. Orangutans were moved off-display to allow the keepers access to the enclosure. Conflict events over enrichment items were rarely observed during the study, and the orangutans generally ate in solitude once they had located an enrichment item, therefore it was considered unlikely that $R / R$ behaviour would be influenced by conflict or competition in this study.

During session recordings, all three orangutans were filmed simultaneously for one hour by a single researcher using two handheld cameras (CoolPix 5700, Nikon, Tokyo Japan; MV550i, Canon, Tokyo, Japan). Footage was captured from the roof of the offdisplay area, which allowed unobstructed views of most of the enclosure. The researcher was within the view of the orangutans, however the potential for observer effects were considered minimal, as all animals were habituated to being on display, and because they had no prior experience (positive or negative) with the researcher. The researcher avoided attracting their attention by wearing dark and neutral clothing, and by remaining quiet and unobtrusive throughout the recording period. Eighteen enrichment sessions were recorded in total over an eight-week period in May and June 2016.

\subsection{Behavioural Coding}

An ethogram of mutually exclusive and exhaustive behaviours was created to facilitate consistent coding of behaviour from the collected video footage (Table 2). A single trained observer coded the behaviours, and a subset of observations were compared with a second experienced observer. Inter-observer reliability (using percentage of agreement taken at 1 min intervals on $8.3 \%$ of the videos totaling 270 intervals) was greater than $80 \%$. Observers were not blind to the experimental hypotheses or the enrichment item but were blind to the enrichment filling type. Coding of behaviour, using focal animal sampling with continuous recording, was carried out from the collected videos with Cowlog observation software [35]. Videos collected from each enrichment session were therefore coded three times-once for each individual orangutan. In total, fifty-four observation hours were coded, comprised of eighteen hours per individual (nine different enrichment items delivered twice; once with a savoury filling and once with a sweet filling). 
Table 1. Enrichment items, filling category $(S A=$ savoury, $S W=$ sweet), and ingredients, used with orangutans at Auckland Zoo.

\begin{tabular}{ccc}
\hline Enrichment Item & Treatment & Treatment Filling \\
\hline \multirow{2}{*}{ Large boxes } & SW & Popcorn, raisins, caraway seeds, and ginger \\
& SA & Popcorn, peanuts, Chinese five spice, and caraway seeds \\
\hline \multirow{2}{*}{ Firehose boxes } & SW & Popcorn, prunes, sesame seeds and mixed spice \\
Firehose with holes & SA & Popcorn, peanuts, poppy seeds, and lemon pepper \\
& SW & Jam and sesame seeds \\
Clothing shapes and hose pipes & SA & Cooked lentils and fennel seeds \\
\hline \multirow{2}{*}{ Sonar tubes } & SW & Popcorn, chopped dates, cinnamon, rosemary, jam, and fennel seeds \\
& SW & Popcorn, peanuts, cinnamon, cooked lentils, and sesame seeds \\
\hline \multirow{2}{*}{ Large iceys } & SA & Popcorn, chopped apricot, fennel seeds, and peppermint essence \\
& SW & Popcorn, peanuts, mixed herbs, and poppy seeds \\
\hline \multirow{2}{*}{ Sacks } & SA & Diluted juice and frozen strawberries \\
Logs & SW & Choysa brown tea, lemons, and ground cloves \\
\hline \multirow{2}{*}{ Noodle pinecones } & SA & Popcorn, mixed spice, dates, and mixed seeds \\
& SW & Popcorn, peanuts, sesame seeds, and curry powder \\
\hline \multirow{2}{*}{ SA } & Cooked rice, stewed quince \\
\hline
\end{tabular}

Table 2. Ethogram of orangutan behaviours used to record enrichment interaction, and regurgitation/reingestion at Auckland Zoo. Behaviours are mutually exclusive of each other.

\begin{tabular}{cr}
\hline Behaviour & Description \\
$\begin{array}{cc}\text { Regurgitation and reingestion } \\
\text { Enrichment interaction/engagement }\end{array}$ & $\begin{array}{c}\text { While sitting, the individual's shoulders are hunched and heaving until vomitus } \\
\text { material has been brought up which is then reingested. } \\
\text { This behaviour may be very subtle, and for Melur this was often accompanied or } \\
\text { preceded by shoulder slapping or face rubbing. }\end{array}$ \\
\hline Eating/foraging enrichment interaction & Individual is engaged with or touching the enrichment item but is not eating/foraging \\
\hline Out of view & Individual is eating food obtained from the enrichment item. \\
\hline Other & Individual is not in view of the camera or the behaviour being performed is not clear. \\
\hline
\end{tabular}

\subsection{Data Analysis}

Data analysis was undertaken using $R$ version 3.6.0 [36]. Individuals were analysed separately because the sample size was too small $(n=3)$ for population-level analysis, but the amount of data per individual $(n=18)$ was sufficient for individual-level analyses. Both descriptive and inferential statistics are presented in the results. As the orangutans moved out of sight of the camera on occasion during filming, behavioural data were converted from seconds into \% of time in sight. Out of sight time had a mean of $27.3 \%$ of the observation period (range: $1.4 \%$ to $71.7 \%$ ).

\subsubsection{Analysis 1}

The effect of enrichment engagement time and eating time on the amount of $R / R$ behaviour were analysed separately using Spearman's correlations. Friedman's tests (base $R$ package) were then used to determine whether filling type affected the amount of $R / R$ behaviour. Enrichment item was included as a blocking factor because each item was included twice in the study. Both Spearman's and Friedman's tests are non-parametric so 
there are no assumptions around normality, and other requirements (e.g., data types and independence between blocking factors for the Friedman's tests) were met.

\subsubsection{Analysis 2}

To determine if $R / R$ behaviour was more likely to occur with sweet or savoury filling, $\mathrm{R} / \mathrm{R}$ data were converted into binary form ( 0 -absent, 1 - present during the session), and analysed using a mixed effects binary logistic regression, with the canonical link function (lme4 package [37]). Enrichment item was included as a random factor to account for the repeated measures design. No continuous explanatory variables were included in this analysis, therefore assumptions around linearity and collinearity did not apply.

\subsubsection{Analysis 3}

To determine if enrichment engagement time was affected by filling type, a linear mixed model was used (lme4 package [37]), specifying a normal distribution with the canonical link function. Again, enrichment item was included as a random factor to account for the repeated measures design. Visualisation of residual plots suggested that model fit for the female orangutans were sub-optimal, however this was remedied by (natural) $\log$ transforming engagement time after adding a constant of one (because zero values cannot be log transformed). Marginal means were extracted from the model using the emmeans package [38]).

\section{Results}

3.1. Descriptive Statistics for Regurgitation/Reingestion (R/R) Behaviour, Enrichment Engagement, and Eating Time

Behaviours are presented here as a percentage of the observation time (maximum of $1 \mathrm{~h}$ ) rather than minutes to adjust for any time out of sight. The three orangutans spent, on average, only a small amount of time performing R/R. Charlie's mean ( \pm standard error) $\mathrm{R} / \mathrm{R}$ time was $1.46 \%( \pm 1.1)$, while the two females, Melur and Wanita, were $2.02 \%( \pm 0.8)$ and $3.75 \%( \pm 1.5)$, respectively.

Charlie spent $6.63 \%( \pm 1.4)$ of his time engaged with the enrichment. Enrichment interaction by the female orangutans was around three times higher than shown by Charlie: $22.69 \%( \pm 4.0)$ for Melur, and $20.35 \%( \pm 4.5)$ for Wanita. A range in engagement time from $0 \%$ to $81 \%$ was observed between different enrichment items with their respective fillings. The percentage of time that each orangutan spent eating the enrichment filling was $6.82 \%$ $( \pm 2.5)$ for Charlie, $19.36 \%( \pm 4.4)$ for Melur, and 14.02\% $( \pm 3.8)$ for Wanita.

3.2. The Influence of Filling Type, Eating and Engagement Time on the Amount of R/R Behaviour Performed

Enrichment filling type (sweet/savoury) did not affect the amount of $\mathrm{R} / \mathrm{R}$ performed by Charlie $\left(\chi^{2}=2, \mathrm{df}=1, p=0.157\right)$ or Melur $\left(\chi^{2}=1.8, \mathrm{df}=1, p=0.180\right)$. Wanita tended to perform more $\mathrm{R} / \mathrm{R}$ during sweet enrichment compared to savoury $\left(\chi^{2}=3.6, \mathrm{df}=1\right.$, $p=0.06)$ (Figure 1), although it did not reach the criterion for significance $(p<0.05)$. Eating time had no correlation with $\mathrm{R} / \mathrm{R}$ for the two females (Melur: $\mathrm{R}_{\mathrm{s}}=-0.38, p=0.127$; Wanita: $\left.R_{s}=-0.11, p=0.658\right)$ while Charlie showed a positive but non-significant trend $\left(R_{s}=0.42\right.$, $p=0.08$ ). There was no correlation between engagement time and the amount of $R / R$ behaviour performed for any of the orangutans: Melur $\left(R_{S}=0.29, p=0.236\right)$, Charlie $\left(R_{s}=0.15, p=0.542 ;\right)$, Wanita $\left(R_{s}=0.12, p=0.630\right)$. 

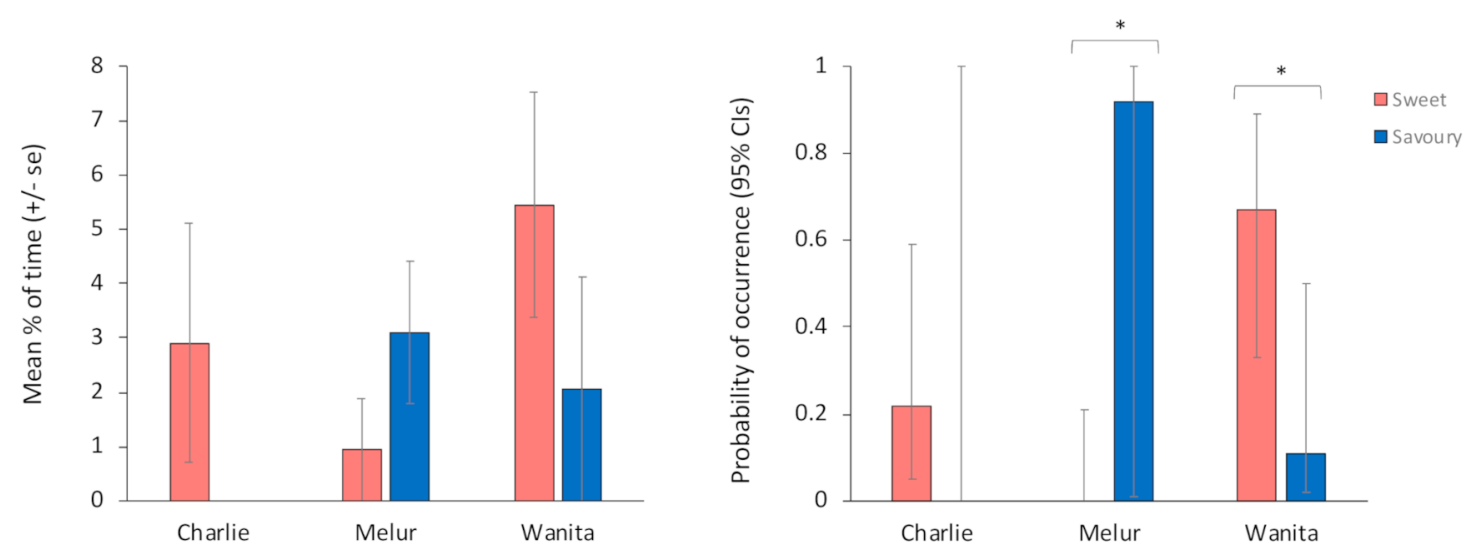

Figure 1. Mean \% of time (+/- se) (left) and probability of occurrence (95\% CIs) (right) of regurgitation/reingestion behaviour by three orangutans at Auckland Zoo within one hour of being provided enrichment filled with either a sweet or savoury filling. Significant differences $(p<0.05)$ are denoted by *

\subsection{The Influence of Filling Type on the Probability of R/R Occurrence}

While enrichment filling type did not increase or decrease the amount of $R / R$ performed, it did affect the probability that it would occur at least once during an observation period. Wanita had a higher probability of performing R/R with sweet enrichment compared to savoury enrichment $\left(\chi^{2}=4.73, p=0.030\right)$ (Figure 1$)$. In contrast, Melur was more likely to $\mathrm{R} / \mathrm{R}$ with savoury enrichment compared to sweet $\left(\chi^{2}=4.65, p=0.03\right)$. The probability of Charlie performing $\mathrm{R} / \mathrm{R}$ had no relationship to whether the enrichment item was filled with sweet or savoury filling $\left(\chi^{2}=2.39, p=0.122\right)$.

\subsection{The Influence of Filling Type on the Amount of Engagement Time}

Enrichment engagement time was unaffected by whether the filling type was sweet or savoury for the two female orangutans (Melur: $\chi^{2}=0.02, \mathrm{df}=1, p=0.968$; Wanita: $\left.\chi^{2}=0.33, \mathrm{df}=1, p=0.565\right)$. The male orangutan spent significantly more time engaging with savoury filled enrichment $(8.32 \% \pm 1.9)$, compared to sweet $(4.93 \% \pm 1.9)\left(\chi^{2}=5.19\right.$, $\mathrm{df}=1, p=0.023)$, when the effect of enrichment item was controlled for.

\section{Discussion}

In the current study, all three orangutans exhibited $\mathrm{R} / \mathrm{R}$ behaviour, although it did not occur in every enrichment session. It was hypothesised that $R / R$ behaviour would occur more with sweet-filled enrichment compared to savoury, based on existing literature $[1,11,29]$. This was partially supported as one of the females, Wanita, was more likely to perform $R / R$, and also showed a trend towards higher amounts of $R / R$, with sweet-filled enrichment compared to savoury. However this pattern did not hold for all individuals as the second female, Melur, was more likely to perform R/R with savoury-filled enrichment. $R / R$ behaviour by the male was not affected by enrichment filling type, in either probability of occurrence or the amount performed. These findings give some support to the suggestions from published literature that a reduction of sweet food within zoo orangutan diets may lower R/R [1], however it is evident that individual level behaviour and motivations should also be determined. Ideally, future research would incorporate observations over a longer period of time to determine the consistency of results, and during non-feeding contexts as well.

It was anticipated that $R / R$ behaviour would decrease as enrichment engagement time increased. Charlie, the male orangutan, showed low levels of enrichment engagement within the study (mean of $\sim 6 \%$ of observation time), although it was higher for savoury enrichment, while the female orangutans engaged at a much higher level $(\sim 20 \%$ of the time). Contrary to our expectation, no relationship was evident between engagement time and the amount of $\mathrm{R} / \mathrm{R}$ performed for any orangutan. The enrichment items included in this study were a subset of the zoo's existing program and were included because they 
could be used as a vehicle for delivering sweet or savoury fillings in a standardised way. Although two of the three orangutans engaged well with the enrichment, it may be that this was not at a level that would impact R/R, and the inclusion of more complex items such as puzzle boxes and computer-based enrichment could have a greater effect [39-42]. Such devices are being increasingly used to enhance captive ape welfare and can be designed to provide cognitive stimulation whilst increasing foraging time [43].

If engagement time can be viewed as a form of foraging behaviour, our findings contrast with much of existing literature that shows a negative relationship between foraging time and $R / R$ performance $[11,14,17]$. This may be due to the specificity of our zoo sample, although one point of difference is that many of these studies include the provision of browse, which is typically high in fibre [44], and requires mechanical processing via chewing, both of which influence satiety [45]. Similarly, unpublished prior research involving Auckland Zoo orangutans, found that a browse-only diet reduced R/R compared to one containing sweet foods [46]. In the current study, enrichment items and fillings were not specifically designed to increase foraging time or to act as a browse substitute and one limitation was that the enrichment program could not be altered for the purposes of the research. Alternative enrichment fillings may have a different effect on $R / R$, for example, by replacing fruit and commercial biscuits with fibrous vegetables [29]. It is possible that an interaction effect between engagement time and $R / R$ is dependent on the type or processing requirements of the associated filling.

One hypothesis for $\mathrm{R} / \mathrm{R}$ performance is that it may serve to prolong feeding experiences, motivation for which also decrease with satiety [3]. Struck and colleagues [23] proposed a similar explanation when $R / R$ behaviour performed by their focal chimpanzee did not decline in response to high fibre vegetables and increased when savoury forage material was provided. Although foraging time increased overall, the forage material was still able to be consumed quickly compared to browse, and it was therefore suggested that this may have led to insufficient satiation [23]. In the current study mean eating behaviour ranged from $6 \%$ of the observation time (Charlie) to $18 \%$ (Wanita). Only Charlie showed any relationship between eating time and $\mathrm{R} / \mathrm{R}$ however this was a positive trend, while a negative relationship would be expected if longer eating time led to greater satiety and less $R / R$. Regardless, food preference may remain as a motivator for $R / R$ behaviour, and would explain why Melur and Wanita had contrasting patterns for the probability of $R / R$ occurrence with sweet and savoury enrichment. Melur also appeared to show "superstitious behaviour" [47], such as shoulder slapping, as a precursor to R/R. Superstitions occur by conditioning when an association is formed between an unrelated behaviour and a desired consequence [48]. This suggests that $R / R$ may be intrinsically rewarding if the precurser behaviour is performed in order to trigger the $R / R$. Useful future studies could incorporate preference testing [49] or behavioural economics [50] to determine if individual level food preferences are indeed a driver of $R / R$ behaviour in orangutans.

This is a small study of three individuals, which cannot elucidate species-wide patterns on the reasons behind R/R behaviour. However, this study illustrates the importance of considering animal welfare at the individual level, because individuals may respond very differently to their environment [51]. Our research does suggest that individual orangutans vary in their engagement with sweet and savoury food, and their propensity to perform $R / R$ in relation to this. $R / R$ is a prevalent behaviour in captive great apes [1], which could potentially undermine welfare efforts [5]. At present, $R / R$ literature is largely compiled of localised studies with restricted small sample sizes. Multi-zoo collaborations such as the 'Many Primates' [52] initiative may offer opportunities for continuing R/R research with larger animal numbers, which could incorporate social influences or statistically test individual characteristics such as sex, age or personality.

Several avenues exist for future research, for example, the causal nature of $R / R$ in relation to the continuous feeding hypothesis [3] could be examined by using intermittent feeders that deliver sweet and savoury food at a standardised rate. Importantly, R/R performance outside of the post-prandial period should also be studied to clearly establish 
whether it only occurs after food provisioning. Lastly, while the amount of time spent in $R / R$ behaviour for our orangutans was reasonably low on average, if $R / R$ causes oesophageal, oral or dental damage [20], even low incident rates are concerning. Further investigation should be conducted into the potentially deleterious physical consequences of regurgitant acid during $\mathrm{R} / \mathrm{R}$ performance, and the implications for welfare.

Author Contributions: Conceptualization, A.R., R.N. and K.D.; methodology, A.R., R.N. and K.D.; formal analysis, K.D.; investigation, R.N.; resources, A.R.; data curation, R.N. and K.D; writingoriginal draft preparation, H.J. and K.D.; writing—review and editing, H.J., K.D., R.N. and A.R.; supervision, K.D. and A.R. All authors have read and agreed to the published version of the manuscript.

Funding: This research received no external funding.

Institutional Review Board Statement: No experimental interventions were introduced for the purpose of this research project and all data was collected observationally therefore animal ethics approval was not required for this study, in accordance with the New Zealand Animal Welfare Act 1999.

Data Availability Statement: The data presented in this study, and the corresponding analysis R script are available on request from the corresponding author. The data are not publicly available due to permission restrictions.

Acknowledgments: We would like to acknowledge the support given by Auckland Zoo primate keepers and volunteers, and the contributions of the individual orangutans Charlie, Melur and Wanita who were observed in this study.

Conflicts of Interest: The authors declare no conflict of interest.

\section{References}

1. Hill, S.P. Regurgitation and reingestion' (R/R) in great apes: A review of current knowledge. Int. Zoo Yearbook 2018, 52, 62-78. [CrossRef]

2. Melfi, V.A. There are big gaps in our knowledge, and thus approach, to zoo animal welfare: A case for evidence-based zoo animal management. Zoo Biol. 2009, 28, 574-588. [CrossRef] [PubMed]

3. Lukas, K.E. A review of nutritional and motivational factors contributing to the performance of regurgitation and reingestion in captive lowland gorillas (Gorilla gorilla gorilla). Appl. Anim. Behav. Sci. 1999, 63, 237-249. [CrossRef]

4. Strombeck, D.R. Small Animal Gastroenterology; Stonegate Publishing: Davis, CA, USA, 1979.

5. Hill, S.P. Do gorillas regurgitate potentially-injurious stomach acid during "regurgitation and reingestion?". Anim. Welf. 2009, 18, 123-127.

6. Cooper, J. Gorilla Pathology and Health with a Catalogue of Preserved Materials; Cooper, J.E., Hull, G., Eds.; Academic Press: London, UK, 2017.

7. Butcher, F.; (Melbourne Zoo, Melbourne, Australia). Personal communication, 2020.

8. Baker, K.C.; Easley, S.P. An analysis of regurgitation and reingestion in captive chimpanzees. Appl. Anim. Behav. Sci. 1996, 49, 403-415. [CrossRef]

9. Baker, K.C. Straw and forage material ameliorate abnormal behaviors in adult chimpanzees. Zoo Biol. 1997, 16, 225-236. [CrossRef]

10. Herrelko, E.S.; Buchanan-Smith, H.M.; Vick, S.J. Perception of available space during chimpanzee introductions: Number of accessible areas is more important than enclosure size. Zoo Biol. 2015, 34, 397-405. [CrossRef]

11. Cassella, C.M.; Mills, A.; Lukas, K.E. Prevalence of regurgitation and reingestion in orangutans housed in North American zoos and an examination of factors influencing its occurrence in a single group of bornean orangutans. Zoo Biol. 2012, 31, 609-620. [CrossRef] [PubMed]

12. Miller, L.J.; Tobey, J.R. Regurgitation and reingestion in bonobos (Pan paniscus): Relationships between abnormal and social behavior. Appl. Anim. Behav. Sci. 2012, 141, 65-70. [CrossRef]

13. Lukas, K.E.; Hamor, G.; Bloomsmith, M.A.; Horton, C.L.; Maple, T.L. Removing milk from captive gorilla diets: The impact on regurgitation and reingestion (R/R) and other behaviors. Zoo Biol. 1999, 18, 515-528. [CrossRef]

14. Fuller, G.; Murray, A.; Thueme, M.; McGuire, M.; Vonk, J.; Allard, S. Behavioral and hormonal responses to the availability of forage material in Western lowland gorillas (Gorilla gorilla gorilla). Zoo Biol. 2018, 37, 23-34. [CrossRef]

15. Ting, C.Y. Orangutan Behaviour in Captivity: Activity Budgets, Enclosure Use and the Visitor Effect. Master's Thesis, National University of Singapore, Singapore, 2011.

16. Birkett, L.P.; Newton-Fisher, N.E. How abnormal is the behaviour of captive, zoo-living chimpanzees? PLoS ONE 2011, 6 . [CrossRef] [PubMed]

17. Gould, E.; Bres, M. Regurgitation in gorillas: Possible model for human eating disorders (Rumination/bulimia). Dev. Behav. Pediatrics 1986, 7, 314-319. [CrossRef] [PubMed] 
18. Pizzutto, C.S.; Sgai, M.G.F.G.; Lopes, D.A.; Pessutti, C.; Nunes, A.; Furtado, P.V.; de Oliveira, C.A.; Guimarães, M.A. Relation between the level of self-mutilation and the concentration of fecal metabolites of glucocorticoids in captive chimpanzees (Pan troglodytes). Wildl. Med. 2015, 35, 62-66.

19. Baker, K.C. Benefits of positive human interaction for socially housed chimpanzees. Anim. Welf. 2004, 13, 239-245. [PubMed]

20. Monagas, J.; Ritwik, P.; Kolomensky, A.; Acosta, J.; Kay, D.; Clendaniel, L.; Hyman, P.E. Rumination syndrome and dental erosions in children. J. Pediatric Gastroenterol. Nutr. 2017, 64, 930-932. [CrossRef] [PubMed]

21. Masi, S.; Cipolletta, C.; Robbins, M.M. Western lowland gorillas (Gorilla gorilla gorilla) change their activity patterns in response to frugivory. Am. J. Primatol. 2009, 71, 91-100. [CrossRef]

22. Wich, S.A.; Atmoko, U.S.U.; Setia, T.M.; van Schaik, C.P. Orangutans: Geographic Variation in Behavioral Ecology and Conservation; Oxford University Press: Oxford, UK, 2009.

23. Struck, K.; Videan, E.N.; Fritz, J.; Murphy, J. Attempting to reduce regurgitation and reingestion in a captive chimpanzee through increased feeding opportunities: A case study. Lab. Anim. 2007, 36, 35-38. [CrossRef]

24. Hill, S.P. Behavioural and Physiological Investigations of Welfare in Captive Western Lowland Gorillas (Gorilla gorilla gorilla). Ph.D. Thesis, Cambridge University, Cambridge, UK, 2004.

25. Morrogh-Bernard, H.C.; Husson, S.J.; Knott, C.D.; Wich, S.A.; van Schaik, C.P.; van Noordwijk, M.A.; Lackman-Ancrenaz, I.; Marshall, A.J.; Kanamori, T.; Kuze, N.; et al. Orangutan activity budgets and diet: A comparison between species, populations and habitats. In Orangutans: Geographic Variation in Behavioral Ecology and Conservation; Wich, S.A., Utami Atmoko, S.S., Setia, T.M., van Schaik, C.P., Eds.; Oxford University Press: Oxford, UK, 2008.

26. Jaeggi, A.V.; Dunkel, L.P.; van Noordwijk, M.A.; Wich, S.A.; Sura, A.A.L.; van Schaik, C.P. Social learning of diet and foraging skills by wild immature Bornean orangutans: Implications for culture. Am. J. Primatol. 2010, 72, 62-71. [CrossRef]

27. Cabana, F.; Jasmi, R.; Maguire, R. Great ape nutrition: Low-sugar and high-fibre diets can lead to increased natural behaviours, decreased regurgitation and reingestion, and reversal of prediabetes. Int. Zoo Yearb. 2018, 52, 48-61. [CrossRef]

28. Birke, L. Effects of browse, human visitors and noise on the behaviour of captive orang utans. Anim Welf. 2002, 11, 189-202.

29. Less, E.H.; Lukas, K.E.; Bergl, R.; Ball, R.; Kuhar, C.W.; Lavin, S.R.; Raghanti, M.A.; Wensvoort, J.; Willis, M.A.; Dennis, P.M. Implementing a low-starch biscuit-free diet in zoo gorillas: The impact on health. Zoo Biol. 2014, 33, 74-80. [CrossRef] [PubMed]

30. Seiffert, S. Ten years of browse provision at ZSL London Zoo and ZSL Whipsnade Zoo: What have we learned and where are we going? In Proceedings of the 10th European Zoo Nutrition Conference, Marwell Zoo, Winchester, UK, 17-20 January 2019.

31. Kim-McCormack, N.N.E.; Smith, C.L.; Behie, A.M. Is interactive technology a relevant and effective enrichment for captive great apes? Appl. Anim. Behav. Sci. 2016, 185, 1-8. [CrossRef]

32. Mellen, J.; Macphee, M.S. Philosophy of Environmental Enrichment: Past, Present, and Future. Zoo Biol. 2001, 226, 211-226. [CrossRef]

33. Maple, T.; Perdue, B. Environmental enrichment. In Zoo Animal Welfare; Springer: Berlin/Heidelberg, Germany, 2013.

34. Robbins, A.; (Auckland Zoo, Auckland, New Zealand). Personal communication, 2016.

35. Pastell, P. Cowlog-Cross-platform application for coding behaviours from video. J. Open Res. Softw. 2016, 4. [CrossRef]

36. R Core Team. R: A Language and Environment for Statistical Computing; R Foundation for Statistical Computing: Vienna, Austria, 2020.

37. Bates, D.; Mächler, M.; Bolker, B.; Walker, S. Fitting linear mixed-effects models using lme4. J. Stat. Softw. 2015, 67, 1-48. [CrossRef]

38. Lenth, R. Emmeans: Estimated Marginal Means, aka Least-Squares Means. Available online: https://CRAN.R-project.org/ package $=$ emmeans (accessed on 15 October 2020).

39. Clark, F.E.; Gray, S.I.; Bennett, P.; Mason, L.J.; Burgess, K.V. High-tech and tactile: Cognitive enrichment for zoo-housed gorillas. Front. Psychol. 2019, 10, 1-15. [CrossRef]

40. Egelkamp, C.L.; Ross, S.R. A review of zoo-based cognitive research using touchscreen interfaces. Zoo Biol. 2019, 38, 220-235. [CrossRef]

41. Perdue, B.M.; Clay, A.W.; Gaalema, D.E.; Maple, T.L.; Stoinski, T.S. Technology at the zoo: The influence of a touchscreen computer on orangutans and zoo visitors. Zoo Biol. 2012, 31, 27-39. [CrossRef]

42. Yamanashi, Y.; Hayashi, M. Assessing the effects of cognitive experiments on the welfare of captive chimpanzees (Pan troglodytes) by direct comparison of activity budget between wild and captive chimpanzees. Am. J. Primatol. 2011, 73, 1231-1238. [CrossRef] [PubMed]

43. Clark, F. Cognitive enrichment and welfare: Current approaches and future directions. Anim. Behav. Cogn. 2017, 4, 52-71. [CrossRef]

44. Chapman, C.A.; Lambert, J.E.; Rothman, J.M. Primate foraging strategies and nutrition: Behavioural and evolutionary implications. In The Evolution of Primate Societies; University of Chicago Press: Chicago, IL, USA, 2012; pp. $145-167$.

45. Campbell, C.L.; Wagoner, T.B.; Foegeding, E.A. Designing foods for satiety: The roles of food structure and oral processing in satiation and satiety. Food Struct. 2017, 13, 1-12. [CrossRef]

46. Andrew, G.; Large, M.; Adams, N.; Robbins, A. Dietary browse reduces frequency of regurgitation and reingestion events in captive bornean orang-utans (Pongo pygmaeus). Unpublished work. 2020.

47. Foster, K.R.; Kokko, H. The evolution of superstitious and superstition-like behaviour. Proc. R. Soc. B Biol. Sci. 2008, 31-37. [CrossRef] 
48. Fernandez, E.J.; Timberlake, W. Superstition revisited: Sex, species, and adventitious reinforcement. Behav. Process. 2020, 170. [CrossRef]

49. Verspeek, J.; Stevens, J.M.G. Food preference and nutrient composition in captive bonobos (Pan paniscus). Primates $2020,61$. [CrossRef]

50. Mason, G.; Farland, D.M.C.; Garner, J. A demanding task: Using economic techniques to assess animal priorities. Anim. Behav. 1998, 55, 1071-1075. [CrossRef]

51. Hill, S.P.; Broom, D.M. Measuring zoo animal welfare: Theory and practice. Zoo Biol. 2009, 28, 531-544. [CrossRef]

52. Many Primates; Altschul, D.M.; Beran, M.J.; Bohn, M.; Call, J.; Detroy, S.; Duguid, S.J.; Egelkamp, C.L.; Fichtel, C.; Fischer, J.; et al. Establishing an infrastructure for collaboration in primate cognition research. PLoS ONE 2019, 14, e0223675. 